\title{
DEVELOPMENT OF THE MANAGEMENT OF ORGANIZATIONS, TAKING INTO ACCOUNT THE RISK-BASED APPROACH
}

\author{
Vladimir I. Avdiiskii ${ }^{1}$ \\ Vyacheslav M. Bezdenezhnykh ${ }^{2}$ \\ Nadezhda M. Yartseva ${ }^{3}$
}

\begin{abstract}
In the formation of new model approaches to analyzing the economy from mega-, macro- to meso- and microlevels, the shift in the focus of assessing the world, regional and national markets and business from the traditionally limited number of macro-indicators of the state of the economy (GDP, profit, growth rate, inflation, exchange rate etc.) to the analysis of complex indicators of the well-being of society (quality of life, income level of various population groups, quality of education, health care, investment structure, etc.) should be taken into account. One of the main objectives of the study was to find the right risk management tools. For this, cases were analysed in which various methods of managing the socioeconomic sphere were used. Myths and
\end{abstract}

stereotypes about the behaviour of people in this area were identified. Risk management is a complex and delicate area of scientific research; therefore, creative thinking was required in adapting the research methodology to get around the difficulties and provide a rich overview for study. The problem of introducing risk-based approach (RBA) both in the processes of analyzing the state and development trends of the economy and in the regulation (control) process in various regulatory scenarios also requires a deep study of these issues both at the methodological and applied levels. This problem has significant differences from the usual tasks of RBA in the problems of analysis and regulation of the development processes of complex socio-economic systems.

\footnotetext{
${ }^{1}$ Department of Economic Security and Risk Management, Financial University under the Government of the Russian Federation, Leningradsky Ave., 49, Moscow, 125993, Russian Federation. E-mail: v.avdiiskii6121@tanu.pro

${ }^{2}$ Department of Economic Security and Risk Management, Financial University under the Government of the Russian Federation, Leningradsky Ave., 49, Moscow, 125993, Russian Federation

${ }^{3}$ Department of Finance and Currency and Credit Relations, Russian Foreign Trade Academy, Ministry for the Economic Development of the Russian Federation, Vorobyovskoe Shosse, 6A, Moscow, 119285, Russian Federation
} 
GÉNERO E

INTERDISCIPLINARIDADE
Vol no 02 | no 01 | ISSN: 2675-7451

https://www.periodicojs.com.br/index.php/gei/index
Keywords: economic models, legal nature, human (organisational) activity, society.

\section{INTRODUCTION}

Currently, risk management is perceived as a tool for any business sector. In a global economy and high volatility due to market uncertainty, risk management is critical for decision makers to achieve high productivity gains. In certain industries, risk management should be given special consideration due to the potential impact of project failure on public safety or the environment, for example in the mining sector due to perceived risk, feasibility studies and uncertainty. Studying the laws of processes in the economy, throughout its history, researchers regularly meet (encounter), and sometimes they themselves create various myths about these laws. Over time, these myths can acquire and even acquire the status of a widely accepted point of view, a scientific concept or a scientific program. For example, the assumption that people always proceed in their decisions from the goal of obtaining their own benefits and make rational decisions based on long-term interests is not being realized in practice. This is indicated by the works of D. Kahneman, A. Tversky (2000) and other researchers.

In fact, the theory of behavioral economics, twice awarded the Nobel Prize in economics, shows that people choose decisions contrary to their or public interests, more often than not realizing this interest and benefit for themselves and society. Essentially, these irrational decision-making approaches are unpredictable, unsystematic, and often erroneous. People are easily carried away, distracted, and even easier to be deceived, by their decisions creating risks for organizations and the entire system of relations as a whole. Therefore, the first and completely trivial conclusion is that every time a theory proceeds from the fact that people are selfish, independent, rational subjects who pursue their own benefit, such theory is mistaken. A whole block (layer) of economic theoretical models about the usefulness and rationality of the subject's behavior in market conditions is collapsing.

The concept of "risk management" has become not only convenient and 
widely accepted in theory and practice, but also useful for justifying the policy of choosing a risk management strategy. Apparently, either we cannot talk about control (or regulation) of risk in its understanding as the possibility of damage, or we need to change the objectsubject relationship. The subject is the observer, but the controller remains the same, therefore the object must be indicated more carefully, accurately, and in detail. Trying to remove this contradiction by introducing the possibility of fixing quantitative parameters of risk, a number of studies supplement the interpretation of "risk" with a reference to its probabilistic nature. In a number of risk management standards, for example, in the first version of the standard developed in Australia and New Zealand, the concept of risk is described as "... a combination of probability and outcome" (Organ and Stapleton, 2016). Therewith, the previously mentioned pessimistic "down-to-earth" approach to risk as the probability of a negative and undesirable effect for an economic entity of deviations (dispersion) of the possible implementation of a risk event in reality from those predicted in the future is often preserved. There is a substitution of the concepts of risk and risk events, which do not coincide.

Risk management is an issue left to the discretion of the organisation's technology department (Organ and Stapleton, 2019). Therefore, systems developers tend to reduce the importance of the business implications of their technical decisions. System development and risk management activities have not been integrated, but are carried out independently of each other (Barlow et al., 2015; Domingues et al., 2017; Organ and Stapleton, 2019). Risk-based research is complex and multifaceted, and researchers are trying to reduce this complexity by focusing on specific areas such as security or project management. A variety of risk causation has not been recognised in how risk is generated, studied, or managed. This reductionist emphasis in risk management can be seen in risk management methodologies, namely methods that depend on the accepted definition and measure of risk, lists of ideal remedies that ignore the unique characteristics of the organisation, or methods that make social systems inferior to technical requirements. (Gladwin et al., 1995; Ardalan, 2011). Conventional system approaches to risk 
GÉNERO E

INTERDISCIPLINARIDADE
Vol no 02 | no 01 | ISSN: 2675-7451

https://www.periodicojs.com.br/index.php/gei/index

have been criticised for being too narrow

to consider perspectives. Such approaches do not allow to see the risk from all sides and take the necessary measures to prevent it.

The content of risk can only refer to a person acting, seeking, making his choice or simply living and trying to achieve their goal (as he understands it). Risk management in such an environment, as one of the mechanisms for resolving conflicts and their harmonisation, has not only a socioeconomic, but also a legal nature (Yu et al., 2015; Crevel et. al., 2014; Hilber and Gabbert, 2020). The risk is achieved under the condition of interaction of elements of a complex system, including: acting from their standpoint on the subject; control and change over time; external environment of the subject's functioning, which also changes over time, as a system of higher order.

One of the main objectives of the study was to find the right risk management tools. For this, cases were analysed in which various methods of managing the socio-economic sphere were used. Myths and stereotypes about the behaviour of people in this area were identified.

\section{MATERIALS METHODS}

Risk management is a complex and delicate area of scientific research; therefore, creative thinking was required in adapting the research methodology to get around the difficulties and provide a rich overview for study. The question types are exploratory in nature and require a flexible outline to explore the challenges of risk management. Case studies allow for multiple sources of evidence. Practical limitations also influenced the choice of methodology. The main difficulty was gaining access to companies and individuals with experience in risk management. This meant that methods such as sound theory were not suitable for this study. While every effort was made to ensure the privacy of the participants, they felt the need to speak and discuss only general terms. In such a situation, an exploratory approach, such as action research, was inappropriate. Keeping these issues in mind, this paper used a case study approach.

Considering risk as a person's choice in the category of utility, the proposed definition of "risk" is "...a 
GÉNERO E

INTERDISCIPLINARIDADE
Vol no 02 | no 01 | ISSN: 2675-7451

https://www.periodicojs.com.br/index.php/gei/index sense of satisfaction with the expected changes in the quality of life in the future and the corresponding expected change in the prevailing quality of life, which the person may have expected to sacrifice for the future". This definition is helpful. Thus, it, firstly, introduces a person (organisation as a product of human activity) into the system of relations (the risk of this human activity). Secondly, we have significantly expanded the range of goals of human (organisational) activity. Nevertheless, the works of Nobel Prize winners in economics R. Thaler, D. Kahneman (Tversky and Kahneman, 1979) say that a person often makes his choice, despite using it. In this case, the risk as satisfaction is difficult to identify and measure according to the results of its possible manifestations. However, the size of the risk (more precisely, the results of its implementation) is one of its distinguishing features.

\section{RESULTS AND DISCUSSION}

Effective risk management is considered the main competitive advantage that determines a company's survival and success in an uncertain global environment. The global financial crisis has focused on the proper identification, analysis and management of key corporate risks, as inadequate risk assessment and management has been identified as one of the main causes of bankruptcy or financial difficulties in many organisations around the world. Consequently, inadequate risk management has become an issue of broader social interests, leading to various regulatory actions.

The second question on this topic is how the market affects the subject with his subjective ideas about rationality and usefulness in decision making. A free market is free only conditionally, it can function because it has borders and rules, because there is control over the implementation of these rules, because there are economic and legal mechanisms to enforce the rules. It is easy to trace the example of even such a fairly liberal market in Singapore. The value and usefulness of a product or service is created by expanding opportunities to balance supply and demand in the market, access to information and other limited market resources, and attracting as many market actors and decision makers to the market as possible. If profit assessment reflects the new usefulness and value, but only 
partially. Indeed, profit, gross income, are not a very accurate method of determining real value and business performance. A local grocery store, a supplier of gas, coal or firewood, drinking water or electricity are more valuable (in the sense that it is difficult to live without it) than a jewelry store, but at the same time, a jewelry store or a posh restaurant have much more profit.

It can be assumed that profit is often an indicator of short-term imbalance in supply and demand, or the arbitrariness of power over pricing, but not the value of the goods (services) produced. Wealthier people can pay more, for example, for a brand, and not benefit, shifting the balance of consumption, but this does not mean that the value of such a product is greater. More accurate measurements of value can be made if you try to evaluate the significance for the consumer, and not on the profitability for the manufacturer of the goods (services) in the market.

Another common myth - the goal of society is to maximize the profit of the manufacturer. Since it was discussed a little earlier, profit is not a very good measure of the value of labor spent for the consumer. Things such as quality of life, a living wage, social and economic stability, social justice and the formation of semantic social attitudes are more significant for society and the state on the strategic forecast horizon (we will leave aside short-term electoral interests). This shifts the focus of assessing value and usefulness to the sphere of education, culture (including science), healthcare - the humanitarian sphere of society. Otherwise, the development of society can have significant difficulties and give rise to new threats and possible risky events. One more conclusion can be made. At present, the growing turbulence (ambiguity) of the context and the absence of methodologically sound decision-making methods taking into account possible risk consequences, the accepted practice of evaluating profitability as a key growth factor is becoming an important factor, but it is not decisive or exhaustive characteristics of evaluating a product (service) in the market. So, according to J. Stiglitz (2019), "the Russian leadership in the era of B. Yeltsin made two major mistakes in the field of economic policy. One of them is the creation of incentives that led more to withdrawing profits than to achieving wealth". 
Another common and popular market myth is that stock prices reflect the value of the company. So, it may be easier to count, and even considering the intangible asset, goodwill, or know-how. But regularly arising questions of the underestimation or revaluation of business assets existing in practice, firstly, show the relativity and momentary nature of such assessments, secondly, form financial "bubbles" and "overheats" of the financial market, and thirdly, push markets to slip into economic depressions and crises. In the most applied practical sense, the price of a stock reflects only what several people in the conditional market decided (recall the previously mentioned subjectivity and irrationality of such decisions) to exchange paper for another paper today. Literally this is how until recently the Rothschild Commission determined such a basic characteristic of the market as the price of an ounce of gold on the London Metal Exchange. Or another example, a company produces a much sought-after product (coffee, aluminum, rolled metal, grain, etc.), but due to a statement made by some official who knows little about economy, the share price may change by a percentage or more. The owner lost (or acquired), according to a conditional estimate, several billions in one currency or another (for example, O. Deripaska as the main owner of Rusal aluminum enterprises). But the company successfully continues its work, produces products that are very popular on the market, the usefulness and value of which is only growing. Tomorrow, estimates will change again, even if the company itself has not changed in terms of the value of its products. Why do we need such an assessment of assets or profits, perhaps for paying taxes, also for business plans, possible lenders and restless competitors (although lenders need more convincing arguments than just profit) Apparently, a non-obvious correlation is shown between how traders evaluate a company in the market and how much benefit the company actually brings, what in this sense its value and real usefulness are. This ambiguity of relations gives rise to threats and risks that also require appropriate consideration.

Any socio-economic regulated system corresponds to a certain level of risk as a condition for its development. Uncertainty is a characteristic of the complexity and instability of the market, which is a factor in choosing a variety of 
development paths, but not a feature of development. With this amendment, it is possible to formulate the theorem "The ratio of the limits of uncertainty and risk of a complex economic system" (Avdiyskiy and Bezdenezhnykh, 2011; 2017), based on the following provisions describing the developing socioeconomic system:

1. Any socio-economic process has a certain value (measure) of the uncertainty of the environmental conditions in which this process occurs, and the value (measure) of the risk of functioning, which acts as the control parameters of a synergetic system characteristics of complexity of the developing system.

2. Any socio-economic process is described by a certain corresponding stability of the functioning of the interval (range) risk management system (controllability based on their measurement, assessment, regulation, monitoring), i.e. characteristics of controllability of the developing system.

3. The socio-economic process describes both the minimum and maximum levels of environmental uncertainty and the risks of the operation (processing), within which it is economically efficient and safe operation, underestimation leads to the termination of development (negative dynamics), and exceedance of the maximum level - to destruction of the system - the characteristic stability of the developing system.

Too often, technical failure is greatly compounded by human error as the process unfolds. In one such case, the company developed a technical disaster plan, which meant that the technical infrastructure would be available within thirty minutes of the disaster. When the disaster did strike, the firm was able to bring its technical infrastructure online within 30 minutes. However, because they did not plan how they would restore the organisational and management procedures associated with the use of the new infrastructure in case of a disaster, the business itself faced great difficulties. The plans focused solely on technology, but did not adequately prepare the organisation to use technology in a real-world disaster recovery situation. The technology recovery was successful, but the system (organisation and technology) recovery failed. Solving these problems as a systemic (rather than a technological) problem significantly increases the work of systems engineering research, 
GÉNERO E

INTERDISCIPLINARIDADE
Vol no 02 | no 01 | ISSN: 2675-7451

https://www.periodicojs.com.br/index.php/gei/index especially in the area of international stability.

The International Federation of Automation and Management's Technical Committee on Technology, Culture and International Stability has identified this kind of systems approach as very important in the management of natural disasterssuch as in Japan (Organ and Stapleton, 2012), as well as other types of system failure, namely the contribution of technological risk factors in the recent financial crisis (Khachaturyan and Klicheva, 2020). In a world in which there are rapid changes in the economic, financial, political and social environment, in a world where uncertainty reigns, ever higher risks arise that affect the process of economic development of the world economy. In this context, risk management can be seen as the art of making decisions in an uncertain environment against the background of identifying, quantifying, analysing and managing the risks that affect the organisation. In this study, one can see what possible mistakes can be made in risk management. The main criterion for assessing the quality of management and predicting further actions should not be stereotypes about human behaviour in critical situations.
As the study demonstrates, the existing myths sit quite firmly in the minds of people. They focus on the propensity of specialists to selfish behaviour, trying to profit from market knowledge.

\section{CONCLUSIONS}

Concluding the analysis of the problems of the theory of analysis of modern economics, we can draw several general conclusions:

1. The current state, processes and development trends of national and world economic systems require the development of fundamentally new theoretical economic models adequate to the market, reflecting real changes in the world in the near future and in the long term.

2. In the formation of new model approaches to analyzing the economy from the mega-, macro- to meso- and microlevels, one should take into account the shift in the focus of assessing the world, regional and national markets and business from the traditionally limited number of macro-indicators of the state of the economy (GDP, profit, growth rate, inflation, exchange rate, etc.) to the analysis of complex indicators of the well-being of society 
(quality of life, income level of various population groups, quality of education, health care, investment structure, etc.). It should be emphasized that macroindicators of the state of economic systems are not canceled and are used in existing calculation models, but their predicted "strength" should be supplemented by a new model analysis based on a risk-based approach, taking into account the distinguished trend of assessing the current economic development.

3. It is especially important in the light of the topic discussed in this article to emphasize the first (intermediate) conclusion indicated earlier on the limited rationality of decisions made in politics and economics at all levels of a complex socio-economic system from the mega to the micro level. This leads to an increase in the riskogenicity of the adopted strategies and development tactics, respectively, the importance of the active development of a risk-based approach to solving emerging regulatory problems. This requires a wide professional development and application of a risk-based approach (RBA) in building models of analysis of the modern economy.
4. The problem of introducing RBA both in the processes of analyzing the state and development trends of the economy, and in the regulation (control) process in various regulatory scenarios also requires an in-depth study of these issues both at the methodological and applied levels. This problem has significant differences from the usual ROP problem in the problems of analysis and regulation with respect to the distinctive points noted in the first three points of the conclusions. Currently, there are numerous studies, including scholars of the Financial University under the Government of the Russian Federation, on resolving this problem, but so far no unified methodologically verified approach has been developed, which further emphasizes the acuteness of the issues being resolved.

\section{References}

Ardalan K. Globalization and information technology: Four paradigmatic views. Technology in Society, 2011, 33(1-2), 59-72.

Avdiyskiy V.I., Bezdenezhnykh V.M. Uncertainty, variability and inconsistency in the objectives of the risk analysis of behavior of economic 
systems. Effective Crisis Management, 2011, 3, 46-61.

Avdiyskiy V.I., Bezdenezhnykh, V.M. Theory and practice enterprise risk management. Moscow: KnoRus, 2017.

Barlow S.M., Boobis A.R., Bridges J., Cockburn A., Dekant W., Hepburn P., Houben G.F., König J., Nauta M.J., Schuermans J., Bánáti D. The role of hazard- and risk-based approaches in ensuring food safety. Trends in Food Science \& Technology, 2015, 46(2), 176-188.

Crevel R. W., Baumert J. L., Baka, A., Houben G. F., Knulst A. C., Kruizinga A. G. Madsen C. B. Part II: development and evolution of risk assessment for food allergens. Food and Chemical Toxicology, 2014, 67, 262-276.

Domingues M.S.Q., Baptista A.L.F., Diogo M.T. Engineering complex systems applied to risk management in the mining industry. International Journal of Mining Science and Technology, 2017, 24(4), 611-616

Gladwin T.N., Krause T.-S., Kennelly J.J. Beyond eco-efficiency: Towards socially sustainable business. Sustainable Development, 1995, 3(1), 35-43.

Hilber I., Gabbert S. Choosing the best for preventing the worst: A structured analysis of the selection of risk management options in REACH restriction dossiers. Regulatory Toxicology and Pharmacology, 2020, $118,44-54$.

Kahneman D., Tversky A. Choices, values, and frames. Cambridge: Cambridge University Press, 2000.

Khachaturyan M.V., Klicheva Ye.V. Development of Ownership Risk Management Systems as the Basis for Ensuring the Economic Sustainability of Russian Organizations in a Pandemic. Modern Management Technology, 2020, 3(93), article number 9303.

Organ J., Stapleton L. A socio-technical systems framework for risk management in financial services: Some empirical evidence from a case study of the Irish Banking Crisis. IFAC-PapersOnLine, 2019, 52(25), 148-153.

Organ J., Stapleton L. Information Systems Risk through a Socio-Technical Lens: Future directions in Systems Risk Research. Proceedings of the International Federation of Automation and Control International Conference on International Stability and Systems Engineering, 2012.

Organ J., Stapleton L. Technologist engagement with risk management practices during systems development? 
Approaches, effectiveness and challenges. AI and SOCIETY, 2016, 31(3), 347-359.

Stiglitz J. Russia is an ever-expanding drama. Financier, Special Issue, 2019, 27-29.

Tversky A., Kahneman D. Prospect theory: An analysis of decision under risk. Econometrica, 1979, 47(2), 263291.

Yu C.-P., Chen H.-G., Klein G., Jiang, R. The roots of executive information system development risks. Information and Software Technology, 2015, 68, 3444. 